\begin{abstract}
Iranica
Abstracta Iranica Revue bibliographique pour le domaine irano-aryen

Volume 37-38-39 | 2018

Comptes rendus des publications de 2014-2016
\end{abstract}

\title{
Émilie Villey (ed.). Les sciences en syriaque
}

Florence Jullien

\section{(2) OpenEdition}

Journals

Édition électronique

URL : http://journals.openedition.org/abstractairanica/43922

DOI : 10.4000/abstractairanica.43922

ISBN : 1961-960X

ISSN : 1961-960X

Éditeur :

CNRS (UMR 7528 Mondes iraniens et indiens), Éditions de l'IFRI

Référence électronique

Florence Jullien, «Émilie Villey (ed.). Les sciences en syriaque », Abstracta Iranica [En ligne], Volume 37-38-39 | 2018, document 1, mis en ligne le 30 décembre 2018, consulté le 28 septembre 2020. URL : http://journals.openedition.org/abstractairanica/43922 ; DOI : https://doi.org/10.4000/ abstractairanica.43922

Ce document a été généré automatiquement le 28 septembre 2020.

Tous droits réservés 


\title{
Émilie Villey (ed.). Les sciences en syriaque
}

\author{
Florence Jullien
}

\section{RÉFÉRENCE}

Émilie Villey (ed.). Les sciences en syriaque. Paris : Geuthner, 2014, IX-351 p., (Études syriaques 11), ISBN 9782705339111.

1 Cet ouvrage fait suite à la $\mathrm{XI}^{\mathrm{e}}$ table-ronde de la société des études syriaques de novembre 2013 consacrée aux textes "scientifiques" conservés en syriaque. Il met en lumière l'importance des échanges que les érudits de Mésopotamie et de Babylonie avaient noué avec les milieux intellectuels alexandrin, constantinopolitain et chypriote aussi, particulièrement aux $\mathrm{VI}^{\mathrm{e}}$ et $\mathrm{VII}^{\mathrm{e}} \mathrm{s}$., sur des sujets aussi variés que la médecine, les mathématiques, l'astronomie, la géographie, la botanique ou encore l'agronomie. L'ample mouvement de traduction de ces traités scientifiques prit un essor exceptionnel à Badgad au IX ${ }^{\mathrm{e}}$ siècle, sous le califat d'al-Ma'mūn, avec la création de la Maison de la sagesse en 832 où s'illustrèrent de grands savants tels Thābit ibn Qurra ou Ḥunayn ibn Isḥaq; la renaissance abbasside dut beaucoup à ces chrétiens bilingues voire trilingues qui firent passer l'héritage grec à l'arabe souvent via le syriaque. De nombreuses productions datent également de cette période. Ce dynamisme est encore bien représenté quatre siècles plus tard avec le maphrien Grigor Bar 'Ebrōyō qui passa les dernières années de son existence à Maragha, dans le nord-ouest de l'Iran, la nouvelle capitale de l'Ilkhanat mongol sous Hülagü (qui y avait fait édifier un célèbre observatoire en 1259 où se distingua l'astronome Nasīr al-Dīn al-Tūsī). Une introduction détaillée (É. Villey, p. 1-8) et le premier article ( Sciences et savants syriaques : une histoire multiculturelle » par M. Debié, p. 9-66) permettent de dresser le contexte d'une histoire multiculturelle dans le domaine des sciences. Les articles sont subdivisés selon les disciplines : textes mathématiques (« Mathématiques en syriaque » par H. Hugonnard-Roche, p. 67-106), géographiques («Les textes géographiques en langue syriaque " par O. Defaux), p. 107-147), astronomiques («Qennešrē et 
l'astronomie aux $\mathrm{VI}^{\mathrm{e}}$ et VII ${ }^{\mathrm{e}}$ siècles » par É. Villey, p. 149-190 ; «L'astronomie syriaque à l'époque islamique » par H. Takahashi, p. 319-337), alchimiques («L'alchimie syriaque et l'œuvre de Zosime » par M. Martelli, p. 191-214), sur l'agriculture (« L'agriculture en syriaque : l'Anatolius Syriacus (“Géoponiques syriaques”) » par C. Guignard, p. 215-252), la médecine («La médecine thérapeutique en syriaque aux $\mathrm{IV}^{\mathrm{e}}-\mathrm{VII}{ }^{\mathrm{e}}$ siècles » par $\mathrm{A}$. Muraviev, p. 253-284), la botanique et la pharmaceutique (« La littérature botanique et pharmaceutique en langue syriaque» par S. Bhayro et R. Hawley, p. 285-318). L'ensemble offre une vue synthétique sur les thèmes abordés, complété d'une bibliographie exhaustive et commode regroupant les textes syriaques (dont les traductions de sources grecques).

\section{AUTEURS}

\section{FLORENCE JULLIEN}

CNRS, Mondes iranien et indien, Paris 